\title{
ChemComm
}

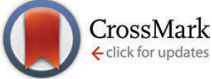

Cite this: Chem. Commun., 2015, 51,10326

Received 12th May 2015

Accepted 22nd May 2015

DOI: $10.1039 / c 5 c c 03955 j$

www.rsc.org/chemcomm

\section{Supramolecular hydrophobic guest transport system based on pillar[5]arene $\uparrow$}

\author{
Zhenhui Qi, Katharina Achazi, Rainer Haag, Shengyi Dong* and \\ Christoph A. Schalley*
}

\begin{abstract}
A pillar[5]arene-based bioactive guest loading system has been developed, which can increase the solubility of the drug norharmane in aqueous medium, and also enable its $\mathrm{pH}$-stimulated release. Furthermore, this supramolecular transport system reduces the toxicity of loaded guest.
\end{abstract}

The development of efficient and responsive guest-loading complexes is not only of fundamental scientific interest, but also exerts significant value for pharmaceutical applications. ${ }^{1}$ Supramolecular structures involving macrocycles have been an intense area of research, because they serve as models for understanding natural supramolecular self-assemblies and molecular recognition motifs, and more importantly, they provide precursors for designing novel nanomaterials for biomedical applications. ${ }^{2}$ Currently, there is an urgent need for methods that improve the solubility of poorly soluble bioactive candidates, because an estimated $40-70 \%$ of new chemical entities belong to Biopharmaceutics Classification System (BCS) Class II, which comprises compounds with low solubility, but high intestinal permeability. ${ }^{3}$ Supramolecular entities, such as host-guest complexes, ${ }^{4}$ supramolecular polymers, ${ }^{5}$ vesicles and micelles, ${ }^{6}$ have gained increased attention in applications as guest transport systems. These entities not only trap high-energy forms of bioactive ingredients owing to their high binding constant $\left(K_{\mathrm{a}}>10^{4} \mathrm{M}^{-1}\right)$, but also expose dynamical, stimuli-responsive, and controllable guest-recognition behaviour, which enables the release of molecules under external stimuli.

Pillar $[n]$ arenes $(\mathrm{P}[n] \mathrm{s})$ are a new class of macrocyclic hosts beside crown ethers, ${ }^{7}$ cyclodextrins,${ }^{8}$ calixarenes, ${ }^{9}$ and cucurbiturils. ${ }^{10}$ The repeating units of $\mathrm{P}[n] \mathrm{s}$ are connected by methylene bridges in the two para-positions, forming rigid pillar-like architectures. ${ }^{11}$ The unique structures and easy functionalization of pillararenes

Institut für Chemie und Biochemie, Freie Universität Berlin, Takustrasse 3, 14195 Berlin, Germany.E-mail: s.dong@schalley-lab.de, c.schalley@fu-berlin.de; Fax: +49 30-838-55817; Tel: +49 30-838-52639

$\dagger$ Electronic supplementary information (ESI) available: Synthetic procedures, characterization, association constant determination, and other materials. See DOI: $10.1039 / \mathrm{c} 5 \mathrm{cc} 03955 \mathrm{j}$ have given them outstanding abilities to selectively bind different kinds of guests and provided a useful platform for the construction of many interesting supramolecular systems, including cyclic dimers, ${ }^{12}$ chemosensors,${ }^{13}$ supramolecular polymers,${ }^{14}$ and transmembrane channels. ${ }^{15}$ However, exploring $\mathrm{P}[n] \mathrm{s}^{\prime}$ applications in biomedical fields, particularly as a drug loading system, is still in its infancy. ${ }^{16}$ The main reason can be ascribed to the limited information available on the biocompability of $\mathrm{P}[n] \mathrm{s}$. Also, little effort has been devoted to gaining insight on their host-guest complexation behaviour with bioactive molecules. ${ }^{17}$ Just recently, for example, Huang's group reported a pillararene-based ternary drug-delivery system with photo-controlled anticancer drug release. ${ }^{17 a}$ Wang et al. described $\mathrm{P}[6]$-derived vesicles that can entrap model drugs and realize controlled release. ${ }^{17 b, c}$ In these $\mathrm{P}[n] \mathrm{s}$-based loading systems, the main design strategy was to introduce suitable guest molecules to construct supramolecular amphiphiles along with $\mathrm{P}[n] \mathrm{s}$ via host-guest chemistry, which could then further assemble into micelles/vesicles. The model drugs were loaded during the preparation of these assemblies and then exposed to dialysis. Apparently, this type of formulation strategy inevitably required several synthetic steps for host/ guest molecules as well as additional purification processes. Moreover, the preparation of large-scale amounts was probably going to be even more costly. To realize loading and release on demand, a simpler, more economic loading system was needed in which the $\mathrm{P}[n] \mathrm{s}$ could directly interact with bioactive molecules.

Herein, we report a supramolecular approach to induce drug transport based on a water-soluble pillar[5]arene. The molecular recognition event facilitated a more soluble hydrophobic drug molecule in aqueous solution. The reversible complexation and decomplexation with drug molecules could be easily monitored and controlled by $\mathrm{pH}$ variation.

As depicted in Scheme 1, two water-soluble pillar[5]arene hosts $\mathbf{1}$ and $\mathbf{2}$ were chosen for this study. The synthesis of $\mathbf{1}$ and 2 was prepared by a "building-block approach" from two wellknown key intermediates that were available from inexpensive starting materials. ${ }^{18}$ Norharmane (NHM) was selected as a hydrophobic drug model to investigate the ability of the loading 

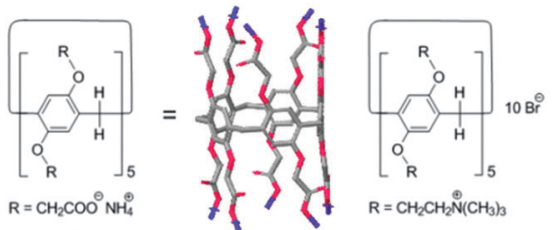

1
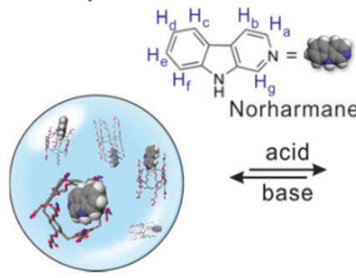

Norharmane

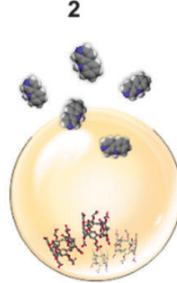

Scheme 1 Chemical structures of water-soluble pillar[5]arenes $\mathbf{1}$ and $\mathbf{2}$, and bioactive model molecule norharmane (NHM).

capacity and potential host-guest properties of 1 and 2. NHM, known also as $\beta$-carboline, is a bioactive alkaloid, which widely exists in animals and plants, ${ }^{19}$ and has been reported to exhibit significant antioxidant abilities and neuroprotective effects against neurotoxins ${ }^{20}$ and potent antitumor, antiviral, antimicrobial, and antiparasitic activities in photodynamic therapy. ${ }^{21}$ In our test approach, we observed a large excess of insoluble solid NHM ( $2 \mathrm{mg}$ ) floating in the tested vial $\left(1 \mathrm{~mL} \mathrm{H}_{2} \mathrm{O}\right)$. However, the excess insoluble NHM could be rapidly dissolved when the certain amount of $\mathbf{1}(20 \mathrm{mg})$ was added to the system under gentle stirring ( $1 \mathrm{~min}, 500 \mathrm{rpm}$ ), which suggests host 1 was able to facilitate the solvation process of hydrophobic bioactive molecule. Under identical conditions, however, compound 2 did not lead to any apparent solubilisation, which indicated that the terminal functional group played a vital role for the selective recognition.

The ${ }^{1} \mathrm{H}$ NMR was recorded to follow the solubilisation process. As shown in Fig. 1, we found that the proton signals of NHM clearly showed upfield shifts upon addition of $\mathbf{1}$. For example, the pyridine ring proton $\left(H_{\mathrm{a}}\right)$ shifted from $8.82 \mathrm{ppm}$ to $8.16 \mathrm{ppm}$, and $H_{\mathrm{d}}$ on the indole moiety moved from $8.25 \mathrm{ppm}$ to $7.70 \mathrm{ppm}$, respectively. All these signal changes were consistent with the shielding effect observed in other NHM-involved complexes. ${ }^{22}$ As expected,

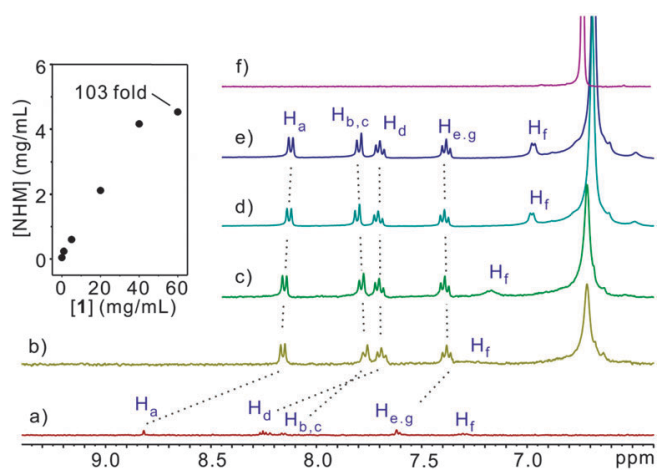

Fig. 1 Partial ${ }^{1} \mathrm{H}$ NMR spectra (400 MHz, $\mathrm{D}_{2} \mathrm{O}, 298 \mathrm{~K}$ ) of (a) the saturated aqueous solution of NHM, and suspensions of a fixed amount NHM $(6.0 \mathrm{mg})$ after addition of (b) $1 \mathrm{mg}$, (c) $5 \mathrm{mg}$, (d) $20 \mathrm{mg}$, (e) $60 \mathrm{mg}$, and (f) only 1 . The inserted figure is a phase-solubility diagram measured for $\mathrm{NHM}$ in the presence of $\mathbf{1}$. the addition of 2 to the suspension of NHM did not cause any significant variation in the ${ }^{1} \mathrm{H}$ NMR spectra (Fig. S1, ESI $\dagger$ ). The detailed phase-solubility diagram (Fig. 1, plot of [NHM] versus [1]) shows the solubility of the drug molecule was thus increased by factor of 100 (up to $4.5 \mathrm{mg} \mathrm{mL}^{-1}$ ) with the assistance of pillararene host (Fig. S3, ESI $\dagger$ ).

We gained more detailed recognition information between host 1 and NHM through UV-vis and fluorescence examinations, since NHM is also known for its excellent chemosensory response and has been widely used as a molecular probe for biophysics studies. $^{23}$ In aqueous medium, the absorption spectrum of saturated NHM solution showed two characteristic bands with maxima at $348 \mathrm{~nm}$ and $372 \mathrm{~nm}$ that correspond to its neutral and cationic forms, respectively (Fig. 2a). With gradual addition of 1 , the band belonging to the neutral form of NHM concomitantly decreased, and the band belonging to the acid form increased, which is due to the shifted ground state of NHM from prototropic equilibrium towards its cationic form. In a fluorescent study, we observed that the blue emission band at $450 \mathrm{~nm}$, ascribed to the cationic form of NHM, was rapidly quenched after addition of $\mathbf{1}$ (Fig. 2b). The Stern-Volmer quenching constant $\left(K_{\mathrm{sv}}\right)$, an indicator of the degree of sensitivity of quencher, was found to be as high as $1.36 \times 10^{5} \mathrm{M}^{-1}$ in our case (Fig. S4, ESI $\dagger$ ), which is even compatible to some reported efficient quenchers with high $K_{\mathrm{sv}}{ }^{24}$
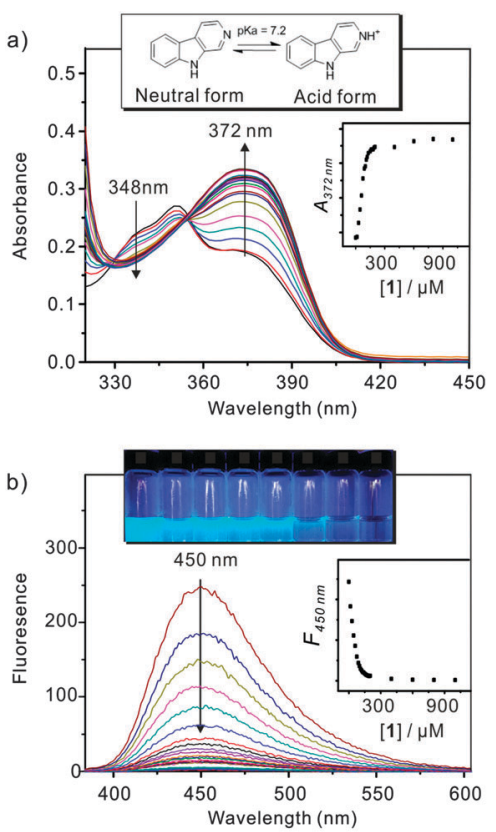

c)

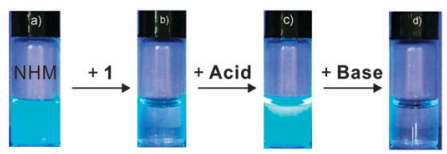

Fig. 2 Variation of the (a) absorption and (b) fluorescence $\left(\lambda_{\text {ex }}=352 \mathrm{~nm}\right)$ spectra of NHM as a function of the concentration of 1 . From the bottom to top of the arrows, the curves correspond to $[1]=0$ to $1.36 \mathrm{mg} \mathrm{mL}^{-1}$. The inserted photos show the fluorescence quenching process $\left(\lambda_{\mathrm{ex}}=365 \mathrm{~nm}\right)$. (c) The $\mathrm{pH}$-triggered reversible complexation and discomplexation processes between 1 and NHM. In all samples, the concentrations of NHM were kept as a constant $44 \mu \mathrm{g} \mathrm{mL}^{-1}$. 
In fact, the fluorescence quenching process usually can be caused by a collision process (dynamic quenching mechanism) or by formation of a complex between quencher and fluorophore (static quenching mechanism).

Here the obtained bimolecular quenching constant $\left(k_{\mathrm{q}}\right)$ has a value of $\sim 10^{12} \mathrm{M}^{-1} \mathrm{~s}^{-1}$ (Fig. S4, ESI $\dagger$ ), which is two orders larger than the maximum value of diffusion-limited rate constant $\left(\sim 10^{10} \mathrm{M}^{-1} \mathrm{~s}^{-1}\right)$ and indicates the observed quenching mechanism is due to complex formation. Moreover, previous studies focusing on natural $\beta$-carboline alkaloids found that the chemical groups with lower oxidation potential facilitated the fluorescence quenching since the protons transferred from the singlet-excited $\beta$-carboline to the receptor. ${ }^{25}$ Considering the relatively low oxidation potential of carboxylates, the rapid quenching process induced by $\mathbf{1}$ could be attributed to the electrostatic interaction between the cationic fluorophore (singlet-excited NHM) and the negative $\mathrm{COO}^{-}$group on 1. In other words, the NHM favourably binds to the rim region where there is a high concentration of carboxylate anion (as illustrated in Scheme 1), instead of being embedded in the cavity of $\mathbf{1}$, which is somewhat unique to many other host-guest complexes based on pillararenes. ${ }^{26}$ However, it was still difficult to determine the cavity's hydrophobic effect upon the complexation. The Job plot showed the complex adapted the 1:1 NHM-1 stoichiometry (Fig. S5, ESI $\dagger$ ), which implied the binding of the first NHM molecule resulted in a structural alternation that was unfavourable for binding the second guest. Using the Benesi-Hildebrand equation, we determined that the binding constants $K_{\mathrm{a}}$ for NHM-1 was $3.4 \times 10^{4} \mathrm{M}^{-1}$ (Fig. S6, ESI $\dagger$ ).

Here the $\mathrm{pH}$-triggered release was achieved because of the pH-sensitivity of carboxylate group. Adding a little excess of hydrochloric acid to a mixed solution of NHM and $\mathbf{1}$ immediately resulted in a fast and obvious phase transition from a clear solution to a turbid colloid (Fig. 2c), which was ascribed to the precipitated carboxylic-acid form of pillar[5]arene $1 .^{16 c}$ Since the fluorescent intensity of NHM under acidic conditions $(\mathrm{pH}=1.5)$ is known to be approximately three times higher than in neutral medium $(\mathrm{pH}=7.0),{ }^{27}$ we can estimate that over $90 \%$ of the complexed drug molecules were released upon the reduction of the $\mathrm{pH}$ value (Fig. S7, ESI $\dagger$ ). The further addition of ammonia changed the system to neutral medium, and the fluorescence of NHM was regained correspondingly.

The cytotoxicity of $\mathbf{1}$ was exemplarily evaluated in different cell lines. Up to a concentration of $300 \mu \mathrm{M} \mathrm{mL}^{-1}$, no cytotoxicity could be observed in human kidney cells (HEK 293), human liver cells (HepG2) and human monocyte cells (THP-1) in a MTS assay (Fig. S8, ESI $\dagger$ ). Furthermore, we tested in vitro cytotoxic activity of the NHM-1 system in A549 cells by MTT (3-(4,5dimethylthiazolyl)-2,5-diphenyltetrazolium bromide) for further applications. We found that the toxicity for NHM obviously decreased after supramolecular complexation (Fig. 3). For example, cells treated with concentrations of $60 \mu \mathrm{g} \mathrm{mL}{ }^{-1} \mathrm{NHM}(367 \mu \mathrm{M})$ showed only a minor reduction in cell viability $(\sim 20 \%)$. In contrast, the relative cell viability of the sample treated with NHM dissolved in methanol sharply reduced $(\sim 95 \%)$. Previous studies showed $\beta$-carboline alkaloids are characteristic for DNA binding. ${ }^{20 b}$

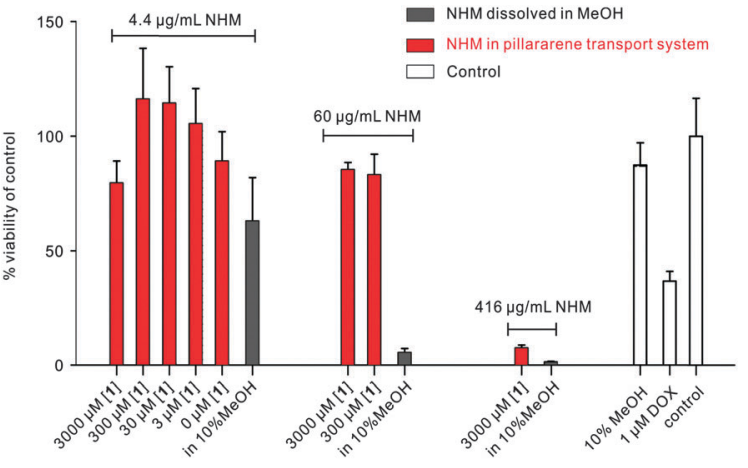

Fig. 3 Cytotoxicity of NHM and its complexes with 1 in human A549 cells.

Particularly at high dose condition, the intercalation between $\beta$-carboline species into DNA may lead to conformational changes and disrupt the normal mechanism of DNA replication, transcription, and repair. ${ }^{21 b}$ Therefore, the observed toxicity reduction could be ascribed to the lowered chance of NHM bound to the DNA in nucleus and mitochondrion of cells. From the above results, it could be demonstrated that this supramolecular induced drug transport system diminished the toxicity of bioactive molecules even at high concentrations of NHM.

In summary, we have presented a versatile, simplified hydrophobic guest transport system based on the pillararene. The introduction of supramolecular interactions between $\mathrm{P}[5]$ derivative and NHM exhibited improvement of the water solubility of the bioactive molecule. Compared with individual NHM, the supramolecular transport system containing both NHM and 1 showed a significant reduction of the drug's cell toxicity, when at higher concentration. Considering that the increased numbers of $\mathrm{P}[n] \mathrm{s}$ homologues $(n=6-14)$ contain larger cavities (in nanosize) and more functional groups, ${ }^{28}$ we believe the pillararenes-based guest transport system has great potential as drug delivery system.

This work was supported by Deutsche Forschungsgemeinschaft (SFB 765) and Focus Area Nanoscale at Freie Universität Berlin. The authors thank Christina Kühl for the assistance of cell viability experiment. Dr Shengyi Dong acknowledges financial support from the Alexander von Humboldt Foundation. The authors acknowledge Dr P. Winchester for proof reading and Dr David Mosser providing HeLa cells.

\section{Notes and references}

1 (a) Z. Laughrey and B. C. Gibb, Chem. Soc. Rev., 2011, 40, 363; (b) K. I. Assaf and W. M. Nau, Chem. Soc. Rev., 2015, 44, 394.

2 (a) Z. Niu and H. W. Gibson, Chem. Rev., 2009, 109, 6024; (b) F. Lei, M. A. Olson, D. Benitez, E. Tkatchouk, W. A. Goddard and J. F. Stoddart, Chem. Soc. Rev., 2010, 39, 17; (c) J. Wu, A. Zawistowski, M. Ehrmann, T. Yi and C. Schmuck, J. Am. Chem. Soc., 2011, 133, 9720; (d) F. Huang and O. A. Scherman, Chem. Soc. Rev., 2012, 41, 5879; (e) S.-L. Li, T. Xiao, C. Lin and L. Wang, Chem. Soc. Rev., 2012, 41, 5950; $(f)$ Y. Ding, P. Wang, Y.-K. Tian and F. Wang, Chem. Commun., 2013, 49, 5951; $(g)$ S. Dong, B. Zheng, F. Wang and F. Huang, Acc. Chem. Res., 2014, 47, 1982; (h) G. Ghale and W. M. Nau, Acc. Chem. Res., 2014, 47, 2150; (i) Z. Qi and C. A. Schalley, Acc. Chem. Res., 2014, 47, 2222; ( $j$ ) G. Stephenson, R. M. Parker, Y. Lan, Z. Yu, O. A. Scherman and C. Abell, Chem. Commun., 2014, 50, 7048; (k) J. A. Foster and J. W. Steed, Angew. Chem., Int. Ed., 2010, 49, 6718. 
3 (a) C. A. Lipinski, J. Pharmacol. Toxicol. Methods, 2000, 44, 235; (b) D. J. Hauss, Adv. Drug Delivery Rev., 2007, 59, 667; (c) C. J. H. Porter, N. L. Trevaskis and W. N. Charman, Nat. Rev. Drug Discovery, 2007, 6, 231.

4 (a) J. Li and X. J. Loh, Adv. Drug Delivery Rev., 2008, 60, 1000; (b) Y. Chen and Y. Liu, Chem. Soc. Rev., 2010, 39, 495; (c) G. Chen and M. Jiang, Chem. Soc. Rev., 2011, 40, 2254.

5 (a) R. Haag, Angew. Chem., Int. Ed., 2004, 43, 278; (b) T. Aida, E. W. Meijer and S. I. Stupp, Science, 2012, 335, 813; (c) S. Biswas, K. Kinbara, T. Niwa, H. Taguchi, N. Ishii, S. Watanabe, K. Miyata, K. Kataoka and T. Aida, Nat. Chem., 2013, 5, 613.

6 (a) S. Nowag and R. Haag, Angew. Chem., Int. Ed., 2014, 53, 49; (b) Y. Wang, S. Song, J. Liu, D. Liu and H. Zhang, Angew. Chem., Int. Ed., 2015, 54, 536.

7 (a) S. J. Loeb and J. A. Wisner, Angew. Chem., Int. Ed., 1998, 37, 2838; (b) H. W. Gibson, N. Yamaguchi, L. Hamilton and J. W. Jones, J. Am. Chem. Soc., 2002, 124, 4652; (c) F. Huang, F. R. Fronczek and H. W. Gibson, J. Am. Chem. Soc., 2003, 125, 9272; (d) H. W. Gibson, N. Yamaguchi and J. W. Jones, J. Am. Chem. Soc., 2003, 125, 3522; (e) W. Jiang and C. A. Schalley, Proc. Natl. Acad. Sci. U. S. A., 2009, 106, 10425; $(f)$ X. Yan, D. Xu, X. Chi, J. Chen, S. Dong, X. Ding, Y. Yu and F. Huang, Adv. Mater., 2012, 24, 362; $(g)$ L. Chen, Y.-K. Tian, Y. Ding, Y.-J. Tian and F. Wang, Macromolecules, 2012, 45, 8412; (h) Z. Qi, P. Malo de Molina, W. Jiang, Q. Wang, K. Nowosinski, A. Schulz, M. Gradzielski and C. A. Schalley, Chem. Sci., 2012, 3, 2073; (i) Z. Qi, C. Wu, P. Malo de Molina, H. Sun, A. Schulz, C. Griesinger, M. Gradzielski, R. Haag, M. B. Ansorge-Schumacher and C. A. Schalley, Chem. - Eur. J., 2013, 19, 10150; (j) Z. Qi, N. L. Traulsen, P. Malo de Molina, C. Schlaich, M. Gradzielski and C. A. Schalley, Org. Biomol. Chem., 2014, 12, 503; (k) Y.-K. Tian, Z.-S. Yang, X.-Q. Lv, R.-S. Yao and F. Wang, Chem. Commun., 2014, 50, 9477.

8 A. Harada, Acc. Chem. Res., 2001, 34, 456.

9 (a) J. S. Kim and D. T. Quang, Chem. Rev., 2007, 107, 3780; (b) D.-S. Guo and Y. Liu, Chem. Soc. Rev., 2012, 41, 5907.

10 (a) K. Kim, Chem. Soc. Rev., 2002, 31, 96; (b) B. Vinciguerra, L. Cao, J. R. Cannon, P. Y. Zavalij, C. Fenselau and L. Isaacs, J. Am. Chem. Soc., 2012, 134, 13133; (c) D. Ma, G. Hettiarachchi, D. Nguyen, B. Zhang, J. B. Wittenberg, P. Y. Zavalij, V. Briken and L. Isaacs, Nat. Chem., 2012, 4, 503.

11 (a) T. Ogoshi, S. Kanai, S. Fujinami, T. Yamagishi and Y. Nakamoto, J. Am. Chem. Soc., 2008, 130, 5022; (b) D. Cao, Y. Kou, J. Liang, Z. Chen, L. Wang and H. Meier, Angew. Chem., Int. Ed., 2009, 48, 9721; (c) Z. Zhang, B. Xia, C. Han, Y. Yu and F. Huang, Org. Lett., 2010, 12, 3285; (d) C. Li, Q. Xu, J. Li, F. Yao and X. Jia, Org. Biomol. Chem., 2010, 8, 1568; (e) M. Holler, N. Allenbach, J. Sonet and J.-F. Nierengarten, Chem. Commun., 2012, 48, 2576; $(f)$ X. Shu, S. Chen, J. Li, Z. Chen, L. Weng, X. Jia and C. Li, Chem. Commun., 2012, 48, 2967-2969; $(g)$ M. P. Sonawane, J. Jacobs, J. Thomas, L. V. Meervelt and W. Dehaen, Chem. Commun., 2013, 49, 6310; (h) T. Adiri, D. Marcianob and Y. Cohen, Chem. Commun., 2013, 49, 7082; (i) H. Zhang, X. Ma, J. Guo, K. T. Nguyen, Q. Zhang, X.-J. Wang, H. Yan, L. Zhu and Y. Zhao, RSC Adv., 2013, 3, 368; (j) C. Li, J. Ma, L. Zhao, Y. Zhang, Y. Yu, X. Shu, J. Li and X. Jia, Chem. Commun., 2013, 49, 1924; (k) L. Wu, Y. Fang, Y. Jia, Y. Yang, J. Liao, N. Liu, X. Yang, W. Feng, J. Ming and L. Yuan, Dalton Trans., 2014, 43, 3835; (l) D.-D. Zheng, D.-Y. Fu, Y. Wu, Y.-L. Sun, L.-L. Tan, T. Zhou, S.-Q. Ma, X. Zha and Y.-W. Yang, Chem. Commun., 2014, 50, 3201; (m) Y.-W. Yang, Y.-L. Sun and N. Song, Acc. Chem. Res., 2014, 47, 1950; (n) H. Chen, J. Fan, X. Hu, J. Ma, S. Wang, J. Li, Y. Yu, X. Jia and C. Li, Chem. Sci., 2015, 6, 197.

12 (a) Z. Zhang, G. Yu, C. Han, J. Liu, X. Ding, Y. Yu and F. Huang, Org. Lett., 2011, 13, 4818; (b) X. Wang, K. Han, J. Li, X. Jia and C. Li, Polym. Chem., 2013, 4, 3998; (c) K. Wang, C.-Y. Wang, Y. Zhang,
S. X.-A. Zhang, B. Yang and Y.-W. Yang, Chem. Commun., 2014, 50, 9458.

13 G. Yu, Z. Zhang, C. Han, M. Xue, Q. Zhou and F. Huang, Chem. Commun., 2012, 48, 2958.

14 (a) Z. Zhang, Y. Luo, J. Chen, S. Dong, Y. Yu, Z. Ma and F. Huang, Angew. Chem., Int. Ed., 2011, 50, 1397; (b) B. Xia, B. Zheng, C. Han, S. Dong, M. Zhang, B. Hu, Y. Yu and F. Huang, Polym. Chem., 2013, 4, 2019; (c) X. Hu, X. Wu, S. Wang, D. Chen, W. Xia, C. Lin, Y. Pan and L. Wang, Polym. Chem., 2013, 4, 4292; (d) X. Wang, H. Deng, J. Li, K. Zheng, X. Jia and C. Li, Macromol. Rapid Commun., 2013, 34, 1856; (e) K. Wang, C.-Y. Wang, Y. Wang, H. Li, C.-Y. Bao, J.-Y. Liu, S. X.-A. Zhang and Y.-W. Yang, Chem. Commun., 2013, 49, 10528; $(f)$ C. Li, K. Han, J. Li, Y. Zhang, W. Chen, Y. Yu and X. Jia, Chem. - Eur. J., 2013, 19, 11892; $(g)$ Z.-Y. Li, Y. Zhang, C.-W. Zhang, L.-J. Chen, C. Wang, H. Tan, Y. Yu, X. Li and H.-B. Yang, J. Am. Chem. Soc., 2014, 136, 8577; (h) N. Song, D.-X. Chen, Y.-C. Qiu, X.-Y. Yang, B. Xu, W. Tian and Y.-W. Yang, Chem. Commun., 2014, 50, 8231; (i) C. Li, Chem. Commun., 2014, 50, 12420; $(j)$ N. Song, D.-X. Chen, M.-C. Xia, X.-L. Qiu, K. Ma, B. Xu, W. Tian and Y.-W. Yang, Chem. Commun., 2015, 51, 5526.

15 W. Si, L. Chen, X.-B. Hu, G. Tang, Z. Chen, J.-L. Hou and Z.-T. Li, Angew. Chem., Int. Ed., 2011, 50, 12564.

16 (a) Y.-L. Sun, Y.-W. Yang, D.-X. Chen, G. Wang, Y. Zhou, C.-Y. Wang and J. F. Stoddart, Small, 2013, 9, 3224-3229; (b) H. Zhang, X. Ma, K. T. Nguyen and Y. Zhao, ACS Nano, 2013, 7, 7853; (c) D.-D. Zheng, D.-Y. Fu, Y. Wu, Y.-L. Sun, L.-L. Tan, T. Zhou, S.-Q. Ma, X. Zha and Y.-W. Yang, Chem. Commun., 2014, 50, 3201; (d) P. Wang, Z. Li and X. Ji, Chem. Commun., 2014, 50, 13114.

17 (a) G. Yu, W. Yu, Z. Mao, C. Gao and F. Huang, Small, 2015, 11, 919; (b) Q. Duan, Y. Cao, Y. Li, X. Hu, T. Xiao, C. Lin, Y. Pan and L. Wang, J. Am. Chem. Soc., 2013, 135, 10542; (c) Y. Cao, X.-Y. Hu, Y. Li, X. Zou, S. Xiong, C. Lin, Y.-Z. Shen and L. Wang, J. Am. Chem. Soc., 2014, 136, 10762.

18 (a) T. Ogoshi, M. Hashizume, T.-A. Yamagishi and Y. Nakamoto, Chem. Commun., 2010, 46, 3708; (b) Y. Ma, X. Ji, F. Xiang, X. Chi, C. Han, J. He, Z. Abliz, W. Chen and F. Huang, Chem. Commun., 2011, 47, 12340.

19 K. Touiki, P. Rat, R. Molimard, A. Chait and R. de Beaurepaire, Psychopharmacology, 2005, 182, 562.

20 (a) H. Haghdoost-Yazdi, S.-S. Hosseini, A. Faraji, D. Nahid and H. Jahanihashemi, Behav. Brain Res., 2010, 215, 136; (b) M. M. Gonzalez, M. Pellon-Maison, M. A. Ales-Gandolfo, M. R. GonzalezBaro, R. Erra-Balsells and F. M. Cabrerizo, Org. Biomol. Chem., 2010, 8, 2543.

21 (a) R. Cao, W. Peng, Z. Wang and A. Xu, Curr. Med. Chem., 2007, 14, 479; (b) C. de Meester, Mutat. Res., 1995, 339, 139.

22 A. Mallick, T. Katayama, Y. Ishibasi, M. Yasuda and H. Miyasaka, Analyst, 2011, 136, 275.

23 A. Chakrabarty, A. Mallick, B. Haldar, P. Das and N. Chattopadhyay, Biomacromolecules, 2007, 8, 920.

24 A. Mallick, M. C. Mandal, B. Haldar, A. Chakrabarty, P. Das and N. Chattopadhyay, J. Am. Chem. Soc., 2006, 128, 3126.

25 Z. Miskolczy, M. Megyesi, L. Biczok and H. Gorner, Photochem. Photobiol. Sci., 2011, 10, 592.

26 (a) P. Wang, Y. Yao and M. Xue, Chem. Commun., 2014, 50, 5064; (b) X. Chi, M. Xue, Y. Ma, X. Yan and F. Huang, Chem. Commun., 2013, 49, 8175; (c) W. Chen, Y. Zhang, J. Li, X. Lou, Y. Yu, X. Jia and C. Li, Chem. Commun., 2013, 49, 7956; (d) J. Fan, H. Deng, J. Li, X. Jia and C. Li, Chem. Commun., 2013, 49, 6343.

27 F. Tomas Vert, I. Zabala Sanchez and A. Olba Torrent, J. Photochem., 1983, 23, 355.

28 T. Ogoshi, N. Ueshima, F. Sakakibara, T.-A. Yamagishi and T. Haino, Org. Lett., 2014, 16, 2896. 